\title{
Placental site trophoblastic tumor: a case report and review of the literature
}

\author{
Jean Bouquet de la Jolinière*, F. Khomsi, Anis Fadhlaoui, Nordine Ben Ali, Jean-Bernard Dubuisson and \\ Anis Feki
}

Unit of Surgical Oncological Gynecology, Clinic of Gynecology and Obstetrics, Cantonal Hospital of Fribourg, Fribourg, Switzerland

Edited by:

Issam Lebbi, Ob-Gyn and Fertility

Private Clinic, Dream Center, Tunisia

Reviewed by:

Frank W. R. C. Vandekerckhove,

University Hospital Ghent, Belgium

Mehmet Ali Vardar, Cukurova

University School of Medicine, Turkey

*Correspondence:

Jean Bouquet de la Jolinière

Cantonal Hospital of Fribourg, 6

Chemin des Pensionnats, Fribourg

1708, Switzerland

e-mail: jean.bouquetdejoliniere@

h-fr.ch
Placental site trophoblastic tumor is rare. They represent a rare form of gestational trophoblastic disease. They occur mainly in women who have a history of miscarriage, termination of pregnancy, or even a normal or pathological ongoing pregnancy. The clinical course is unpredictable. This malignancy has different characteristics from other gestational trophoblastic tumors. Following a clinical case that we encountered and treated, we conducted a literary research and review, focusing primarily on prognostic factors and treatment.

Keywords: Immunochemistry, trophoblastic tumor, placental site, chemotherapy, pregnancy

\section{INTRODUCTION}

Placental site trophoblastic tumor (PSTT) is a rare tumor, representing from 0.23 (1) to $3 \%$ (2) of gestational trophoblastic diseases (GTD). "Up to date" state that 300 cases have been reported in the literature (3). It mainly affects women of childbearing age, after pregnancy.

Placental site trophoblastic tumor differs from other GTD by a slow growth and a relative resistance to chemotherapy.

\section{CLINICAL CASE}

A 30-year-old patient, gravida 1 and para 0 , gave birth naturally and without complications to a boy weighing $3290 \mathrm{~g}$ in May 2011 after a previous normal delivery in 2008 of a girl weighing 2970 g. Five months after her second delivery, the patient presented with bleeding (metrorrhagia). The pelvic echography showed no distinctive characteristics. A slightly high level of betaHCG was observed (see Table 1). The presumed diagnosis was a trophoblastic retention. An operative hysteroscopy allowed the removal of $5 \mathrm{cc}$ material. Its histology demonstrated the presence of several trophoblastic viable cells or nearly pyknotic trophoblastic looking cells without signs of malignancy. A weekly follow-up of beta-HCG was instituted, and the patient was treated with an oestroprogestative contraception.

Given the stagnation of beta-HCG during 2 weeks, a further operative hysteroscopy with $3 \mathrm{cc}$ of product removal was carried out. After proofreading the blades and further immunohistochemical study, the diagnosis of PSTT was elected.

The extensive workup included a thoracic-abdominal-pelvic CT, which showed a large sized uterus displaying a heterogeneous rising with moderate bilateral ecstasy of the uterine veins. A cerebral MRI and a PET-CT did not detect the presence of metastasis. After discussion with the couple, a total hysterectomy with preservation of ovaries was decided. Intraoperative exploration is unremarkable except for bilateral uterine venous ecstasy.
Final histology confirmed a PSTT with a diameter of $23 \mathrm{~mm}$, with infiltration of $>50 \%$ of the myometrium. The immunohistochemistry showed strongly positive tumorous staining for inhibin, partially positive staining for beta-HCG and for HPL (placental lactogenic hormone), and negative staining for p63. In addition, the Mib-1(Ki67) has reached 10-15\% by locations (see Figure 1).

\section{DISCUSSION}

Placental site trophoblastic tumor is a subtype of GTH. These include partial and complete hydatidiform moles, invasive moles, choriocarcinoma, PSTT, and epithelioid trophoblastic tumors (TTE). The last three potential entities are grouped under the term gestational trophoblastic neoplasia, given their potential malignancy (4).

The cell proliferation in GTD comes from the placental trophoblast. It consists of syncytiotrophoblast, cytotrophoblast, and intermediate trophoblast. The syncytiotrophoblastic cells are polynuclear cells that form the external layer, mainly produce human chorionic gonadtropin (HCG) and invade the endometrial stroma. The cytotrophoblasts form the basal layer, whose cells can differentiate in syncytiotrophoblastic cells or intermediate trophoblastic cells. The intermediate trophoblastic cells leave the placenta to restructure the spiral arterioles in order to decrease the blood flow resistance toward the placenta $(4,5)$. PSTTs come from these spiral arterioles (6).

Histologically, PSTTs consist in a proliferation of intermediate trophoblastic cells without chorionic villi infiltrating muscle fibers (7). They are characterized with a vascular invasion, a necrosis, and hemorrhage at a lesser extent than choriocarcinoma, and a bigger tendency to disseminate through the lymphatic track $(3,4)$.

The immunohistochemical analysis shows a strongly positive staining for HPL; a generally weak and focal positive staining for HCG $(3,7,8)$; a diffuse positive staining for cytokeratin (7), a strong positive staining for epidermal growth factor receptor 
(EGFR) and vascular endothelial growth factor (VEGF); and a negative staining for human epidermal receptor2/neu (HER2/neu) and cluster of differentiation 117 (CD117) (3). The pregnancyassociated major basic protein (pMBP), a marker of the intermediate trophoblast, turns out useful in differentiating PSTT from other forms of TTE (9).

As for the tumor's pathogenesis, this remains to be clarified. Hui and colleagues found an absence of Y-chromosome in 20 cases of PSTT with a haploid pair of $\mathrm{X}$ chromosomes. They suggest the paternal X chromosome has a functional role in this tumor, with a more important expression of the genes responsible for growth in the paternal genome (6). Other authors report a predominance of female fetuses (11 female fetuses for 2 male ones) among the pregnancies carried to term that were the source of a PSTT (1).

The first case of PSTT was described in 1976 by Kurman and colleagues on a series of 12 cases, referred to as "trophoblastic pseudo tumor," for a supposed benign pathology. Since then, just fewer than 300 cases have been described in the literature, with an

\section{Table 1 | Evolution of beta-HCG levels.}

\begin{tabular}{lc}
\hline Date & beta-HCG $(\mathbf{U l} / \mathbf{m l})$ \\
\hline 23.04 .2012 & 103 \\
02.05 .2012 & 89 \\
30.05 .2012 & 104 \\
09.07 .2012 & 58 \\
24.07 .2012 & 45
\end{tabular}

assured potential for malignancy. The terminology was therefore adapted to the current PSTT denomination in 1981, through the works of Scully (10).

Placental site trophoblastic tumor can arise during or after a normal pregnancy, a miscarriage, an abortion, or a molar pregnancy, and can occur during post-menopause, years after the last pregnancy $((1,3,7)$, and (11)). A case describes multiple metastases in a 4-month-old male infant who consequently died (12).

The primary tumor site is nearly always located in the corpus or the fundus of the uterus, but two cases of cervical location have been described (13).

The patients' age is between 20 (14) and 63 years old (3), 32 years old on average ( 7$)$. The gap since the last pregnancy is on average 34 months (median of 18 months) after the last-known pregnancy.

In the literature, the mean gestity is 2, 2 (14).

Symptomatology is variable. It can be amenorrhea $(1,14)$, bleeding $((14,15),(1))$, uterine rupture (1), abdominal pain (1), post-menopausal bleeding (1), virilization (16), or symptoms due to metastases $(1,17)$. Cases of nephritic syndrome on membranous glomerulonephritis have been described, regressing after treating the tumor $(18,19)$. Some cases were asymptomatic and only the persistent increase in beta-HCG levels led to the diagnosis (14).

The stage of the illness is determined by the gestational TTE FIGO stage (see Tables 2 and 3 ).

The majority of diagnosed cases are at stage I in the classification of GTD according to FIGO (limited to the uterus), 14 (7) to $31 \%$ (20) of the cases initially with metastases manifested.
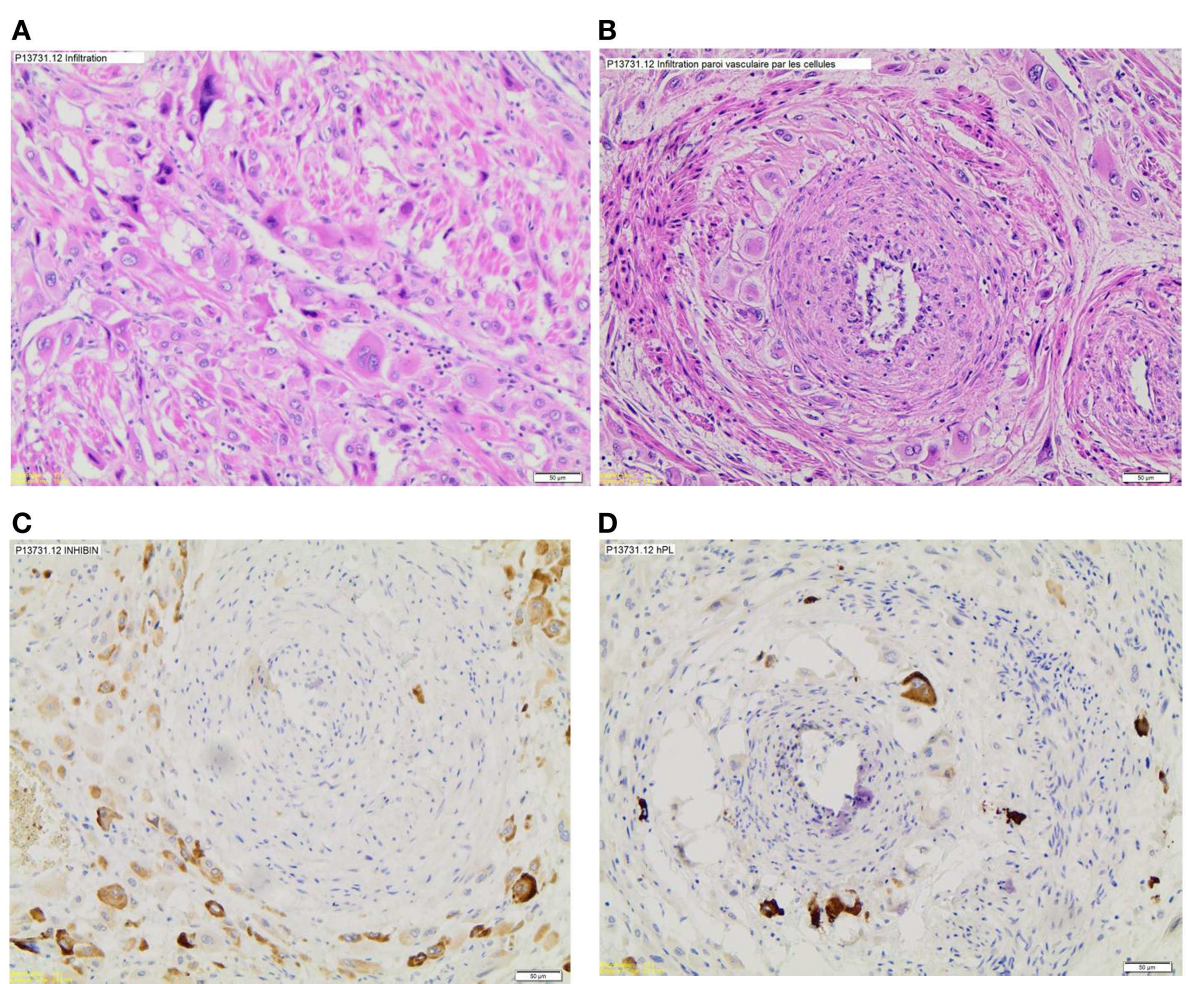

FIGURE 1 | Histologic sections. (A) Myometrium infiltration by tumor cells, (B) vascular invasion, (C) inhibin marking, and (D) HPL marking. 
The metastases sites are (from most frequent to rare): lungs (7), liver $(1,7)$, vagina $(1,7)$, gastrointestinal tract $(7)$, brain $(1,7)$, lymph nodes $(3,7)$, bladder $(7)$, ovary $(7,21)$, omentum $(7)$, thoracic diaphragm $(7)$, pancreas $(1,7)$, spleen $(7)$, kidney $(1)$, bone marrow (7), and scalp (22).

The tendency to metastasize through lymphatic ways seems significant, as $5.9 \%$ of cases have lymphatic metastases during diagnosis or at the time of recurrence. The lymphatic metastases sites are (from most frequent to least frequent): para-aortic (50\%), pelvic $(35.7 \%)$, non-specified retroperitoneal $(14.3 \%)$, inguinal $(7.1 \%)$, renal hilum $(7.1 \%)$, mesenteric $(7.1 \%)$, mediastinal (7.1\%), hilar (7.1\%), and supraclavicular (7.1\%) (3). Lan and colleagues suggest to conduct a retroperitoneal lymphadenectomy on stage 1 patients who have risk factors such as myometrium invasion $>50 \%$ as well as all stages II patients. For other stages, the lymphadenectomy depends on the location and on the resect ability of the other metastases (3).

When looking at the biology, the beta-HCG levels are moderately high, unlike the levels found in the hydatiform moles. In 79\% of cases, the level is lower than $1000 \mathrm{IU} / 1$ and in $58 \%$ of cases, it is lower than $500 \mathrm{IU} / \mathrm{l}$ (23).

Through a routine trans-vaginal ultrasound, one can see the tumor or not, it can have a solid or cystic aspect $(24,25)$. The invasion and destruction of the myometrium vascularization can cause the formation of blood deficiencies and of artery-venous shunt with hemodynamic modifications (26). Some authors have noticed that the tumor vessels have low resistance with high diastolic velocity $(25,26)$. Bettencourt and colleagues suggest a Doppler monitoring to monitor the response to chemotherapy as well as a monitoring of the beta-HCG level (26).

On the MRI, the specifications of PSTT are non-specific (27). In the case of tumors that are invisible on the ultrasound, MRI is particularly interesting to locate the tumor and

Table 2 | Anatomical classification FIGO 2000

\begin{tabular}{ll}
\hline I & Limited to the uterus \\
II & Extended outside the uterus but limited to genital structure \\
III & Extended to lungs with or without known genital tract reached \\
IV & Any other site of metastatis
\end{tabular}

determine the loco-regional extension, thus allowing guidance of treatment (27).

Placental site trophoblastic tumor behavior is characterized by a slower growth, when compared to other TTE, as well as a tendency to diffuse through lymphatic ways. Therefore, they are relatively resistant to chemotherapies (3).

The preferred treatment for PSTT is essentially surgical and is based on hysterectomy $(1,14,15,28)$ with lymphatic sampling $(8$, 29). Conducting a lymphadenectomy at stage 1 seems particularly appropriate in case of risk factors such as a myometrium invasion superior to $50 \%$ (3). Please note that the lymphatic metastases are not listed in the FIGO classification system. The hysterectomy can be inter-adnexal on pre-menopausal patients without a high ovarian carcinoma family risk $(8,24)$.

Several cases of located tumor resection, with the aim to preserve fertility, have been described (30-32). In many cases, an additional hysterectomy was consequently required (inadequate or invaded resection margins, beta-HCG post-operative increase with diffuse myometrium infiltration) (31). In the series described by Saso and colleagues, a case of partial resection through a modified Strasmann procedure allowed to preserve the fertility of a patient. A patient described by Tsuji and colleagues was also treated in such a way as to conserve the uterus with neo-adjuvant chemotherapy by EMA/CO and then tumor resection by laparotomy (30). Shen and colleagues describe six patients successfully treated by a combination of surgery and chemotherapy with uterine conservation. A pregnancy carried to term was reported among one of these patients (32).

In any case, the success level of a conservative treatment is low and this option should be proposed only after an extensive discussion and detailed patient information. It should be reserved for young patients not finding any poor prognosis factors and whose tumor is focal (32).

As far as adjuvant therapies are concerned, Schmid and colleagues have not demonstrated the benefit of chemotherapy for stage I patients (8). On the other hand, a combined surgery and chemotherapy treatment is recommended from stage II onward $(8,28)$. For stage I cases, with poor prognosis factors, such as a long-time interval since the last pregnancy (28), a high mitotic index [Hoekstra et al. - (28)], a vascular invasion, a deep myometrium invasion, an invasion of the serous membrane, or

Table 3 | Stage of the disease at diagnosis.

\begin{tabular}{|c|c|c|c|c|c|c|}
\hline Studies & No. of cases & Stage I (\%) & Stage II (\%) & Stage III (\%) & Stage IV (\%) & Non-set (\%) \\
\hline Chen et al. (15) & 17 & 88.2 & 0 & 11.8 & 0 & \\
\hline Feltmate et al. (14) & 13 & 69.2 & 30.8 & 0 & 0 & \\
\hline Lan et al. (3) & 5 & 40 & 40 & 20 & 0 & \\
\hline Hassadia et al. (1) & 17 & 47.1 & 5.9 & 29.4 & 17.6 & \\
\hline Hoekstra et al. (28) & 7 & 57 & 0 & 0 & 43 & \\
\hline Papadopoulos et al. (23) & 34 & 44 & 24 & 29 & & 3 \\
\hline Shen et al. (32) & 6 & 100 & & & & \\
\hline Zhao et al. (37) & 11 & & & & & \\
\hline
\end{tabular}


for cases with persistence of high post-operative beta-HCG levels, chemotherapy could also be recommended $(8,14,29)$. In a series of cases, Feltmate and colleagues found that the prognosis was improved when starting chemotherapy during the week following the operation (14).

In comparison with other gestational TTE, the response to chemotherapy is lower in PSTT, with $61 \%$ resistance or incomplete response (8).

Comparative data from different chemotherapy schemes are missing. The ones that are generally administrated are: EMA/CO (7) or EMA/EP $(8,14,24,29)$, without a difference being revealed between the EMA/EP, EMA/CO, or EMA schemes, or between the diets with or without platines (8) (see Table 4).

For second-line therapies, there is no consensus, the EMA/EP scheme is proposed in the case of recurrences after EMA/CO (7), or $\operatorname{BEP}(7,33)$ or VIP $(7)$ schemes.

The resection of residual lumps after chemotherapy is recommended, given the lower sensitivity of tumor cells after chemotherapy, which is confirmed by presence of viable tumor cells in the specimen resected after primary chemotherapy $(8,34,35)$.

Table 4 | Protocol of chemotherapy.

\begin{tabular}{ll}
\hline EMA/EP & EMA \\
& $0.5 \mathrm{mg}$ dactinomycin iv J 1 et 2 \\
& $100 \mathrm{mg} / \mathrm{m}^{2}$ etoposide iv J 1 et 2 \\
& $300 \mathrm{mg} / \mathrm{m}^{2}$ methotrexate iv J1 \\
& $15 \mathrm{mg}$ folic ac po $2 \times / \mathrm{j} \mathrm{J} 2$ et 3 \\
& $150 \mathrm{mg} / \mathrm{m}^{2}$ etoposide iv J8 \\
& $75 \mathrm{mg} / \mathrm{m}^{2}$ cisplatin iv J8
\end{tabular}

MAE

$300 \mathrm{mg} / \mathrm{m}^{2}$ methotrexate iv $\mathrm{J} 1$ $15 \mathrm{mg}$ folic ac po $4 \times / \mathrm{j} J \mathrm{~J}$ et 3

$0.5 \mathrm{mg}$ dactinomycin iv $\mathrm{J} 8$ à 10

$100 \mathrm{mg} / \mathrm{m}^{2}$ etoposide iv $\mathrm{J} 8$ à 10

BEP

bleomycin $30 \mathrm{mg}$ iv $\mathrm{J} 1,8,15$

etoposide $100 \mathrm{mg} / \mathrm{m}^{2} \mathrm{~J} 1$ à 5

cisplatin $20 \mathrm{mg} / \mathrm{m}^{2} \mathrm{~J} 1$ à 5

VIP

etoposide $75 \mathrm{mg} / \mathrm{m}^{2} \mathrm{~J} 1$ à 5

ifosfamide $1.2 \mathrm{~g} / \mathrm{m}^{2} \mathrm{~J} 1$ à 5

cisplatin $20 \mathrm{mg} / \mathrm{m}^{2} \mathrm{~J} 1$ à 5
According to Feltmate and colleagues, radiotherapy can be effective for loco-regional control and remains rarely recommended (14).

The factors that are most strongly correlated with poor prognosis, which were found in almost all series, are a high stage according to FIGO $(1,7,8,20,28)$ (Table 5). The value of the FIGO risk scores is controversial (Table 6). According to Hassadia and colleagues, it should not be used $(1,36)$, but Schmid and colleagues's study shows a correlation with survival (8).

Other poor prognosis factors are an interval of more than 24 months since the last pregnancy $(7,8,23,28)$, a level of mitosis higher than 6 in 10 bigs fields $(7,8,14)$, an age older than 34 years $(1,7,8)$, a term birth for the last pregnancy $(7)$, a myometrium invasion of more than $50 \%$ (7), an extensive coagulation necrosis (7), and cells with clear cytoplasm (7).

A beta-HCG level higher than $1000 \operatorname{IU} / 1(7,8)$ is also a poor prognosis factor. On the other hand, this rate is not correlated to the tumor mass (1).

\section{CONCLUSION}

Placental site trophoblastic tumors are exceptional tumors, encountering difficult clinical and histological diagnosis. Immunohistochemistry plays an important role, and our case underlines the importance of reading through the blades several times.

Clinically speaking, their emergence is seldom or not at all predictable because their generally appear after a normal pregnancy.

The usual symptoms are non-specific, such as metrorrhagia or amenorrhea, sometimes years after the last pregnancy. From a biological point of view, the dosage and follow up of beta-HCG levels are interesting for the diagnosis, but one must keep in mind that the levels are not as high as in other GTH.

The only FIGO classification criticism for GTHs is that the lymphatic spread is not taken into account.

In the case of PSTT, the most commonly recognized risk factors are: stage, mitosis rate, elapsed time since last pregnancy at the time of diagnosis, age of the patient, and the degree of myometrium invasion.

With regard to treatment, the leading role of surgery must be underlined, generally through hysterectomy. The possibility of a

Table 5 | Prognostic scores (FIGO 2000).

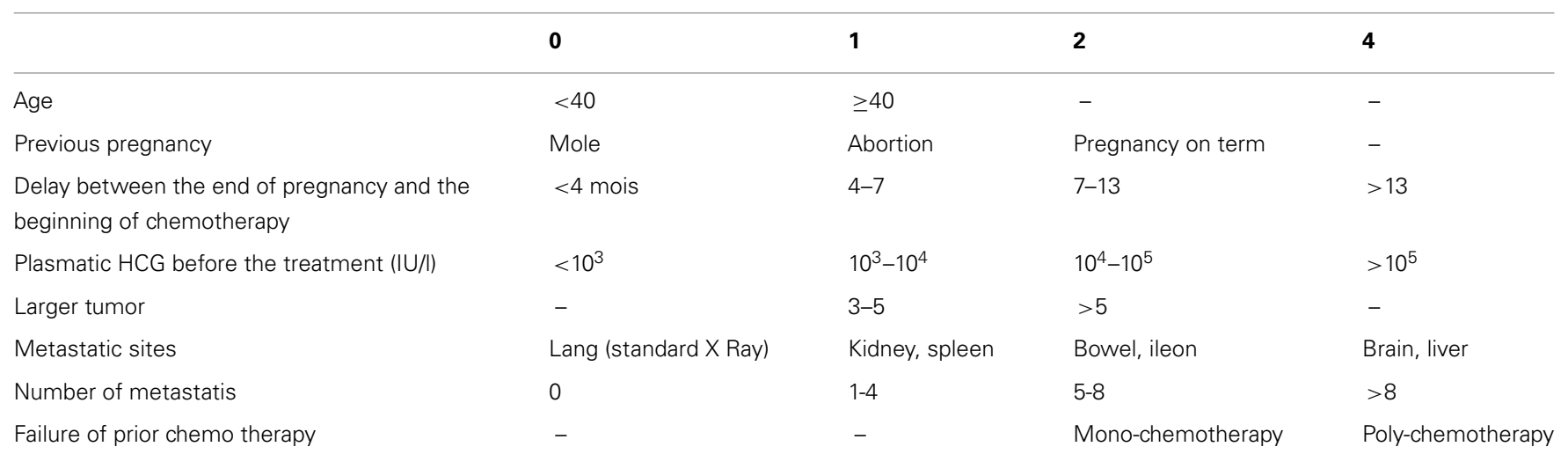


Table 6 | Analysis of literature.

$\begin{array}{lll}\text { Chen et al. (15) } & 17 \text { Cases } & \text { Hysterectomy with or without EMA-CO chemotherapy is a beneficial treatment modality. } \\ \text { Feltmate et al. (14) } \quad 13 \text { Cases } & \text { High mitotic index appears to be an adverse prognostic indicator for recurrence. Hysterectomy remains the } \\ & \begin{array}{l}\text { mainstay of treatment. Chemotherapy is indicated for patients with metastases and may be indicated when the } \\ \text { mitotic index is }>5 \text { Mitoses/10 HPF. Radiation treatment may play a role in recurrent disease but must be } \\ \text { evaluated on a case-by-case basis. }\end{array}\end{array}$

Baergen et al. (7) 55 Cases Significant factors associated with adverse survival in the present series were age over 35 years $(P=0.025)$, interval since the last pregnancy of over 2 years $(P=0.014)$, deep myometrial invasion $(P=0.006)$, stage III or IV $(P<0.0005)$, maximum high $\mathrm{HCG}$ level $>1000 \mathrm{mlU} / \mathrm{ml}(P=0.034)$, extensive coagulative necrosis $(P=0.024)$, high mitotic rate $(P=0.005)$, and the presence of cells with clear cytoplasm $(P<0.0005)$.

Lan et al. (3)

5 Cases

Hassadia et al. (1)

17 Cases

Chang et al. (20)

88 Cases

Schmid et al. (8)

62 Cases

Hoekstra et al. (28)

7 Cases

Papadopoulos et al. (23) 34 Cases

Shen et al. (32)

6 Cases

Zhao et al. (37)
Lymph node metastasis is one way of spread in PSTT. Retroperitoneal node, especially para-aortic node is the most common site of lymphatic spread. EGFR and VEGF may be commonly expressed in PSTT tumors.

Hysterectomy is the primary mode of treatment in the majority of cases. However, chemotherapy can still play a major role when curative surgery is not feasible

FIGO stage is the most important prognostic factor, and complete removal of all lesions provided good outcomes in PSTT patients. For those with unresectable tumors, combination chemotherapy showed a high response rate, but only a few achieved a complete response.

Stage-adapted management with surgery for stage I disease, and combined surgery and chemotherapy for stage II, III, and IV disease could improve the effectiveness of treatment for placental-site trophoblastic tumors. Use of 48 months since antecedent pregnancy as a prognostic indicator of survival could help select patients for risk-adapted treatment.

Advanced FIGO stage, long interval from last known pregnancy to diagnosis, and high mitotic count were adverse prognostic indicators for survival in PSTT. All patients with PSTT should undergo initial hysterectomy with other surgical procedures, as indicated. Chemotherapy, usually EMA/EP, should be used in patients with advanced PSTT and may be considered in patients with FIGO stage I disease with length of time from antecedent pregnancy $>2$ years or high mitotic.

Risk factors for death include lung metastatic involvement (50\%) and an antecedent pregnancy interval of 4 years or more $(100 \%)$. In contrast, those with no extra pelvic disease or a pregnancy interval of less than 4 years had $100 \%$ survival. In two-thirds of patients with disease limited to the uterus, surgery alone was curative.

Fertility-conserving therapy for young women with PSTT would be practicable if the patient is younger than 35 years, strongly desires to preserve fertility and responds well to chemotherapy and conservative surgery, the pathological results of which do not show poor prognostic factors and the gross pathologic type does not present markedly enlarged uterus, diffuse infiltrative, and diffuse multifocal disease within the uterus.

Pathologic diagnosis of PSTT was the gold standard. Multidrug chemotherapy combined with hysterectomy was effective in metastasis cases. treatment conservative of fertility can be discussed with patients who wish to become pregnant again, have high motivation, good prognosis factors, and a thorough discussion.

A lymph node sampling is generally recommended. Chemotherapy is usually not recommended at stage I, but can play a role in cases of poor prognosis. Currently, there is no consensus on the best chemotherapeutic treatment.

\section{REFERENCES}

1. Hassadia A, Gillespie A, Tidy J, Everard J, Wells M, Coleman R, et al. Placental site trophoblastic tumour: clinical features and management. Gynecol Oncol (2005) 99:603-607. doi:10.1016/j.ygyno.2005.06.054

2. Cole ME, Broaddus R, Thaker P, Landen C, Freedman RS. Placental-site trophoblastic tumors: a case of resistant pulmonary metastasis. Nat Clin Pract Oncol (2008) 5(3):171-5. doi:10.1038/ncponc1042
3. Lan C, Li Y, He J, Liu J. Placental site trophoblastic tumor: lymphatic spread and possible target markers. Gynecol Oncol (2010) 116:430-7. doi:10.1016/j.ygyno. 2009.10.056

4. Lurain JR. Gestational trophoblastic disease I: epidemiology, pathology, clinical presentation and diagnosis of gestational trophoblastic disease, and management of hydatidiform mole. Am J Obstet Gynecol (2010) 203:531-9. doi:10. 1016/j.ajog.2010.06.073

5. Whitney KA. Placental site trophoblastic tumor: a case demonstrates the importance of looking beyond a positive pregnancy test for corroborating clinical manifestations. AJN (2009) 109((12):

6. Hui P, Wang HL, Chu P, Yang B, Huang J, Baergen RN, et al. Absence of Y chromosome in human placental site trophoblastic tumor. Mod Pathol (2007) 1:20.

7. Baergen RN, Rutgers JL, Young RH, Osann K, Scully RE. Placental site trophoblastic tumor: a study of 55 cases and review of the literature emphasizing factors of prognostic significance. Gynecol Oncol (2006) 100:511-520. doi:10.1016/j.ygyno.2005.08.058 
8. Schmid P, Nagai Y, Agarwal R, Hancock B, Savage PM, Sebire NJ, et al. Prognostic markers and long-term outcome of placental-site trophoblastic tumours: a retrospective observational study. Lancet (2009) 374:48-55. doi:10.1016/S01406736(09)60618-8

9. Rhoton-Vlasak A, Wagner JM, Rutgers JL, Baergen RN, Young RH, Roche PC, et al. Placental site trophoblastic tumor: human placental lactogen and pregnancy-associated major basic protein as immunohistologic markers. [Abstract]. Hum Pathol (1998) 29(3):280-8. doi:10.1016/S0046-8177(98) 90048-X

10. Scully R, Young R. Trophoblastic pseudo-tumor. [Abstract]. Am J Surg Pathol (1981) 5:75-6. doi:10.1097/00000478-198101000-00010

11. Su YN, Cheng WF, Chen CA, Lin TY, Hsieh FJ, Cheng SP, et al. Pregnancy with primary tubal placental site trophoblastic tumor - a case report and literature review. [Abstract]. Gynecol Oncol (1999) 73(2):322-5. doi:10.1006/gyno.1998. 5318

12. Monclair T, Abeler VM, Kñrn J, Walaas L, Zeller B, Hilstrùm C. Placental site trophoblastic tumor (PSTT) in mother and child: first report of PSTT in infancy [Abstract]. Med Pediatr Oncol (2002) 38:187-91. doi:10.1002/mpo. 1308

13. Wang D, He Y, Hu Y, Yin R. Placental site trophoblastic tumor with unusual presentation in the uterine cervix. Eur J Obstet Gynecol Reprod Biol (2010) 148:96-101.

14. Feltmate CM, Genest DR, Wise L, Bernstein MR, Goldstein DP, Berkowitz RS. Placental site trophoblastic tumor: a 17-year experience at the New England Trophoblastic Disease Center. Gynecol Oncol (2001) 82:415-9. doi:10.1006/gyno. 2001.6265

15. Chen Y, Zhang X, Xie X. Clinical features of 17 cases of placental site trophoblastic tumor. Int J Gynaecol Obstet (2011) 115:204-5. doi:10.1016/j.ijgo.2011.06. 008

16. Nagelberg SB, Rosen SW. Clinical and laboratory investigation of a virilized woman with placental-site trophoblastic tumor. [Abstract]. Obstet Gynecol (1985) 65(4):527-34.

17. Wright JD, Powell MA, Horowitz NS, Huettner PC, White F, Herzog TJ. Placental site trophoblastic tumor presenting with a pneumothorax during pregnancy. [Abstract]. Obstet Gynecol (2002) 100(5 Pt 2):1141-4. doi:10.1016/ S0029-7844(02)02328-1

18. Batra V, Kalra OP, Mathur P, Kavita, Dev G. Membranous glomerulopathy associated with placental site trophoblastic tumour: a case report. Nephrol Dial Transplant (2007) 22:1766-8. doi:10.1093/ndt/gfl786

19. Denny LA, Dehaeck K, Nevin J, Soeters R, van Wijk AL, Megevand E, et al. Placental site trophoblastic tumor: three case reports and literature review. Gynecol Oncol (1995) 59(2):300-3. doi:10.1006/gyno.1995.0026

20. Chang Y-L, Chang T-C, Hsueh S, Huang K-G. Prognostic factors and treatment for placental site trophoblastic tumor-report of 3 cases and analysis of 88 cases. Gynecol Oncol (1999) 73:216-22. doi:10.1006/gyno.1999. 5344

21. Milingos D, Doumplis D, Savage P, Seckl M, Lindsay I, Smith JR. Placental site trophoblastic tumor with an ovarian metastasis. [Abstract]. Int J Gynecol Cancer (2007) 17(4):925-7. doi:10.1111/j.1525-1438.2007.00881.x

22. Yuen YF, Lewis EJ, Larson JT, Wilke MS, Rest EB, Zachary CB. Scalp metastases mimicking alopecia areata. First case report of placental site trophoblastic tumor presenting as cutaneous metastasis. [Abstract]. Dermatol Surg (1998) 24(5):587-91. doi:10.1016/S1076-0512(98) 00026-0

23. Papadopoulos AJ, Foskett M, Seckl MJ, McNeish I, Paradinas FJ, Rees H, et al. Twenty-five years' clinical experience with placental site trophoblastic tumors. [Abstract]. J Reprod Med (2002) 47(6):460-4.

24. Ajithkumar TV, Abraham EK, Rejnishkumar R, Minimole AL. Placental site trophoblastic tumor. Obstet Gynecol Surv (2003) 58(7):484-8.
25. Zhou Y, Lu H, Yu C, Tian Q, Lu W. Sonographic characteristics of placental site trophoblastic tumor. Ultrasound Obstet Gynecol (2013) 41:676-84. doi:10.1002/uog.12269

26. Bettencourt E, Pinto E, Abraúl E, Dinis M, De Oliveira CF. Placental site trophoblastic tumour: the value of transvaginal colour and pulsed Doppler sonography (TV-CDS) in its diagnosis: case report. Eur J Gynaecol Oncol (1997) 18(6):461-4.

27. Brandt KR, Coakley KJ. MR appearance of placental site Trophoblastic tumor: a report of three cases. AJR Am J Roentgenol (1998) 170:485-7. doi:10.2214/ajr. 170.2.9456970

28. Hoekstra AV, Keh P, Lurain JR. Placental site trophoblastic tumor: a review of 7 cases and their implications for prognosis and treatment. [Abstract]. J Reprod Med (2004) 49(6):447-52.

29. Lurain JR. Gestational trophoblastic disease II: classification and management of gestational trophoblastic neoplasia. Am J Obstet Gynecol (2011 ) 204:11-8. doi:10.1016/j.ajog.2010.06.072

30. Tsuji Y, Tsubamoto H, Hori M, Ogasawara T, Koyama K. Case of PSTT treated with chemotherapy followed by open uterine tumor resection to preserve fertility. Gynecol Oncol (2002) 87:303-7. doi:10.1006/gyno.2002.6827

31. Pfeffer PE, Sebire N, Lindsay I, McIndoe A, Lim A, Seckl MJ. Fertility-sparing partial hysterectomy for placental-site trophoblastic tumour. Lancet Oncol (2007) 8:744-6. doi:10.1016/S1470-2045(07)70243-7

32. Shen X, Xiang Y, Guo L, Feng F, Wan X, Xiao Y, et al. Fertility-preserving treatment in young patients with placental site trophoblastic tumors. [Abstract]. Int J Gynecol Cancer (2012) 22(5):869-74. doi:10.1097/IGC.0b013e31824a1bd6

33. Ayas S, Gurbuz A, Karateke A, Cetiner H. Placental site trophoblastic tumor with multiple metastases and complete response to salvage BEP regimen a case report and review of the literature. Med Oncol (2009) 26:96-100. doi:10.1007/s12032-008-9076-9

34. Nieves L, Hoffman J, John Currie GA, Sorosky JI. Placental-site trophoblastic tumor with PET scan-detected surgically treated lung metastasis. Int J Clin Oncol (2008) 13:263-5. doi:10.1007/s10147-007-0721-7

35. Metindir J, Pak I, Ozdilekcan C, Eren E. Chemoresistant placental site trophoblastic tumor with hilar lymph node metastasis: an unusual site of involvement. Gynecol Oncol (2005) 96:552-5. doi:10.1016/j.ygyno.2004.10.030

36. Noal S, Joly F, Leblanc E. Prise en charge d'une tumeur trophoblastique gestationnelle. Revue générale, Gynécologie, Obstétrique et Fertilité (2010) 38:193-8. doi:10.1016/j.gyobfe.2010.01.011

37. Zhao J, Xiang Y, Wan XR, Cui QC, Yang XY. Clinical and pathologic characteristics and prognosis of placental site trophoblastic tumor. J Reprod Med (2006) 51(12):939-44.

Conflict of Interest Statement: The authors declare that the research was conducted in the absence of any commercial or financial relationships that could be construed as a potential conflict of interest.

Received: 23 May 2014; accepted: 29 July 2014; published online: 27 August 2014. Citation: Bouquet de la Jolinière J, Khomsi F, Fadhlaoui A, Ben Ali N, Dubuisson J-B and Feki A (2014) Placental site trophoblastic tumor: a case report and review of the literature. Front. Surg. 1:31. doi: 10.3389/fsurg.2014.00031

This article was submitted to Gynecology and Obstetrics, a section of the journal Frontiers in Surgery.

Copyright (C) 2014 Bouquet de la Jolinière, Khomsi, Fadhlaoui, Ben Ali, Dubuisson and Feki. This is an open-access article distributed under the terms of the Creative Commons Attribution License (CC BY). The use, distribution or reproduction in other forums is permitted, provided the original author(s) or licensor are credited and that the original publication in this journal is cited, in accordance with accepted academic practice. No use, distribution or reproduction is permitted which does not comply with these terms. 